\title{
Small cell lung cancer: updates and future directions
}

\author{
Jose M. Pacheco \\ Division of Medical Oncology, Department of Internal Medicine, University of Colorado Cancer Center, Aurora, CO, USA \\ Correspondence to: Jose M. Pacheco, MD. Assistant Professor, Thoracic Oncology and Developmental Therapeutics, Division of Medical Oncology, \\ Department of Internal Medicine, University of Colorado Cancer Center, 1665 Aurora Court, Room 5309, Mail Stop F704, Aurora, CO 80045, \\ USA. Email: jose.m.pacheco@cuanschutz.edu.
}

Submitted Feb 19, 2020. Accepted for publication Mar 19, 2020.

doi: $10.21037 /$ jtd.2020.02.62

View this article at: http://dx.doi.org/10.21037/jtd.2020.02.62

Small cell lung cancer (SCLC) accounts for $15 \%$ of lung cancers. It strongly associates with cigarette smoking. The biology is characterized by rapid proliferation and early occurrence of metastases. Most patients present at an advanced stage where surgery or potentially curative chemoradiation are not feasible. The 5 -year mortality is very high and there are few long-term survivors.

The treatment landscape of non-small cell lung cancer (NSCLC) has advanced rapidly in the past decade with the discovery of oncogene drivers, development of targeted therapies to inhibit these drivers, the advent of immune checkpoint inhibition and numerous new drug approvals. Unfortunately, the treatment of SCLC has not moved forward to the same degree. Immune checkpoint inhibitors alone in second or subsequent lines or as first-line treatment in combination with platinum plus etoposide were the first new treatment approvals in SCLC in the preceding 20 years. However, the degree of benefit from immunotherapy in SCLC has not been observed to the same degree as in NSCLC. Additionally, there are no approved targeted therapies in SCLC.

Advancements in the biology of this disease have been hindered by difficulties in obtaining good biopsies and resultant challenges in developing effective animal models. Fortunately, these impediments are changing. In this special issue we discuss how the understanding of SCLC disease biology is improving, potential predicative biomarkers that are being investigated and describe some ways these biomarkers could be utilized to improve patient management.

First-line treatment with chemotherapy plus immune checkpoint inhibition recently demonstrated improved survival when compared to chemotherapy alone. However, there is no accepted standard following development of progressive disease on chemoimmunotherapy. In this issue we review first-line chemoimmunotherapy, discuss the literature on second and subsequent line therapy options and evaluate drugs in development for this malignancy. Also, many patients with SCLC present with poor performance status and have been excluded from clinical trials. This special issue attempts to bridge this gap by including original research evaluating outcomes of poor performance status patients to standard systemic therapies.

Radiation has been considered part of the SCLC treatment armamentarium for decades. Conflicting trial data has resulted in the role of prophylactic whole brain radiation being debatable. Additionally, consolidative thoracic radiotherapy was shown to improve 2-year survival in a randomized study. However, the role of consolidative thoracic radiation in the era of firstline chemoimmunotherapy is controversial as this local modality was not allowed on trials investigating chemoimmunotherapy. Stereotactic brain radiation has been suggested to be effective for local tumor control in NSCLC without impairing survival outcomes. The role of this newer radiation modality in treatment of SCLC brain metastases is unclear. Within this issue expert radiation oncologists discuss the role of these radiation modalities in the current treatment landscape.

Additionally, we discuss the role for surgery in the management of SCLC. We also discuss management of paraneoplastic syndromes and superior vena cava syndrome, two important comorbidities seen in SCLC. We would like to thank all the authors for their contributions to this special issue and are confident it will help improve the readers' understanding of SCLC. 


\section{Acknowledgments}

Funding: None.

\section{Footnote}

Provenance and Peer review: This article was commissioned by the editorial office, Fournal of Thoracic Disease for the series "Small Cell Lung Cancer". This article did not undergo external peer review.

Conflicts of Interest: The author has completed the ICMJE uniform disclosure form (available at http://dx.doi. org/10.21037/jtd.2020.02.62). The series "Small Cell Lung Cancer" was commissioned by the editorial office without any funding or sponsorship. JMP served as the unpaid Guest Editor for the series and serves as the unpaid editorial board member of Fournal of Thoracic Disease from Oct 2019 to Sep 2021. Dr. JMP reports personal fees from AstraZeneca, personal fees from Gerson Lehrman Group, personal fees from Hengrui Pharmaceuticals, personal fees from Novartis, personal fees from Pfizer, personal fees from Genentech, personal fees from Takeda, grants from Pfizer, outside the submitted work.

Ethical Statement: The author is accountable for all aspects of the work in ensuring that questions related to the accuracy or integrity of any part of the work are appropriately investigated and resolved.

Open Access Statement: This is an Open Access article distributed in accordance with the Creative Commons Attribution-NonCommercial-NoDerivs 4.0 International License (CC BY-NC-ND 4.0), which permits the noncommercial replication and distribution of the article with the strict proviso that no changes or edits are made and the original work is properly cited (including links to both the formal publication through the relevant DOI and the license). See: https://creativecommons.org/licenses/by-nc-nd/4.0/.

Cite this article as: Pacheco JM. Small cell lung cancer: updates and future directions. J Thorac Dis 2020;12(10):62106211. doi: $10.21037 /$ jtd.2020.02.62 